\title{
Effects of Extremely Low Frequency Electromagnetic Fields on Melanogenesis through p-ERK and p-SAPK/JNK Pathways in Human Melanocytes
}

\author{
Yu-Mi Kim ${ }^{1}$, Sang-Eun Cho ${ }^{1}$, Soo-Chan Kim ${ }^{2}$, Hyun-Joon Jang ${ }^{1}$ and Young-Kwon Seo ${ }^{1, *}$ \\ 1 Department of Medical Biotechnology (BK21 Plus team), Dongguk University, Goyang-si 10326, Korea; \\ kjmtik@nate.com (Y.-M.K.); ssasng41@naver.com (S.-E.C.); filter4u1@naver.com (H.-J.J.) \\ 2 Department of Electric and Electrical Engineering, Institute for Information Technology Convergence, \\ Hankyong National University, Anseong-si 17579, Korea; sckim@hknu.ac.kr \\ * Correspondence: bioseo@dongguk.edu; Tel.: +82-31-961-5154
}

Received: 12 September 2017; Accepted: 3 October 2017; Published: 11 October 2017

\begin{abstract}
This study evaluated frequency-dependent effects of extremely low frequency electromagnetic fields (ELF-EMFs) on melanogenesis by melanocytes in vitro. Melanocytes were exposed to $2 \mathrm{mT}$ EMFs at $30-75 \mathrm{~Hz}$ for 3 days before melanogenesis was examined. Exposure to ELF-EMFs at 50 and $60 \mathrm{~Hz}$ induced melanogenic maturation without cell damage, without changing cell proliferation and mitochondrial activity. Melanin content and tyrosinase activity of cells exposed to $50 \mathrm{~Hz}$ were higher than in controls, and mRNA expression of tyrosinase-related protein-2 was elevated relative to controls at $50 \mathrm{~Hz}$. Phosphorylated cyclic adenosine monophosphate response element-binding protein ( $\mathrm{p}$-CREB) levels were higher than controls in cells exposed to ELF-EMFs at 50-75 Hz. Immunohistochemical staining showed that melanocyte-specific markers (HMB45, Melan-A) were strongly expressed in cells exposed to EMFs at 50 and $60 \mathrm{~Hz}$ compared to controls. Thus, exposure to ELF-EMFs at $50 \mathrm{~Hz}$ could stimulate melanogenesis in melanocytes, through activation of p-CREB and p-p38 and inhibition of phosphorylated extracellular signal-regulated protein kinase and phosphorylated stress-activated protein kinase/c-Jun N-terminal kinase. The results may form the basis of an appropriate anti-gray hair treatment or be applied in a therapeutic device for inducing repigmentation in the skin of vitiligo patients.
\end{abstract}

Keywords: extremely low frequency electromagnetic fields (ELF-EMFs); melanogenesis; MITF; p-CREB; tyrosinase

\section{Introduction}

Melanocytes, which differentiate from melanoblasts, can produce the pigment melanin in a process called melanogenesis. Melanin is present in tissues, such as skin and hair, and in the eyes, and it is synthesized by the melanosome organelle within the melanocyte [1]. Melanin can block a certain amount of ultraviolet radiation (UVR), protecting the skin, and scavenge free oxygen radicals [2].

The skin contains a local defensive melanocortin system to neutralize a wide range of external noxious stimuli (principally UVR) and consists of the pigment melanin and its associated cleaved proopiomelanocortin (POMC) peptides. In cutaneous melanocytes, UVR stimulates POMC formation, with resultant release of several POMC peptides via differential enzymatic cleavage of POMC by prohormone convertases. Consequently, corticotropin (ACTH), and $\alpha-, \beta-$, and $\gamma$-melanocyte-stimulating hormones (MSHs) are produced that can influence melanogenesis. Melanin pigment synthesized in this way can act as a buffer molecule to antagonize the noxious effects of physical, biological, and chemical insults [3,4]. 
The biosynthesis of melanin is a complicated process involving many factors. The important positive regulators of melanin pigmentation include endothelins, histamine, and eicosanoids, acting via interaction with cell surface receptors. Melanocortin-1 receptor (MC1R) is expressed in melanocytes and activation of MCIR by its ligand $\alpha-\mathrm{MSH}$, plays a crucial role in pigmentation by regulating the intracellular levels of cyclic adenosine monophosphate (cAMP) [5]. Besides serving as substrates and intermediates of melanogenesis, it is well known that L-tyrosine and L-dihydroxyphenylalanine (L-DOPA) are also bioregulatory agents, acting not only as inducers and positive regulators of melanogenesis but also as regulators of other cellular functions. Tyrosinase can act both as a regulatory protein by interacting with other proteins and as a regulator of intra- and extracellular concentrations of biologically active molecules (L-tyrosine and L-DOPA). L-DOPA can also regulate cell functions and cellular metabolism through non-receptor-mediated processes that act directly or through intermediates of melanogenesis generated by its non-enzymatic or enzymatic oxidation [6].

Hair follicular melanogenesis involves, sequentially, the melanogenic activity of follicular melanocytes, the transfer of melanin granules into cortical and medulla keratinocytes, and the formation of pigmented hair shafts [7]. The common aging process of graying hair is caused by defects in or the frailty of melanocytes [8]. There are also several associated diseases, such as vitiligo, that occur when melanin synthesis is impaired because the melanocytes are either absent or no longer function [9]. Many possible causes of vitiligo, including immunologic, genetic, stress, and neural mechanisms, and biochemical factors [10] have been proposed, but the etiopathogenesis of the disease is still enigmatic. However, it is believed that the disease is mainly a result of the destruction of melanocytes and obstruction of the melanin synthesis pathway [11].

Many physical treatment methods have been proposed to increase melanin synthesis in the melanocytes of vitiligo patients. Narrowband ultraviolet B (NB-UVB) phototherapy (311-313 nm peak emission) has become a popular treatment option for generalized vitiligo [12]. Significant repigmentation has been reported in a majority of patients with some follicular repigmentation in the remaining $34 \%$, after treating vitiligo patients with a low energy HeNe laser $\left(632 \mathrm{~nm}, 25 \mathrm{~mW} / \mathrm{cm}^{2}\right)$. Consequently, it has been suggested that low level laser light therapy (LLLT) and excimer laser $(308 \mathrm{~nm})$ light may provide an effective alternative treatment for vitiligo patients [13]. These types of phototherapy can increase repigmentation. The laser stimulates melanocyte proliferation through enhanced $\alpha_{2} \beta_{1}$ integrin expression and induces melanocyte growth through upregulation of phosphorylated cAMP response element-binding protein (p-CREB) [14]. Thus, LLLT treatment activates melanoblasts, melanocytes, and other cells, inducing or enhancing melanin synthesis.

Depending on cell type, various stimulation techniques have been used to activate cells, including cyclic pressure, cyclic compressive load, uniaxial strain, perfusion, shear and compression, ultrasound, laser, electrical stimulation, and electromagnetic field, for instance. Physical stimulation, in particular, has been extensively investigated and numerous stimulation devices have been designed and are in clinical use for raising cellular activity levels.

Low frequency low energy pulsed electromagnetic fields (PEMFs) have recently become a research focus to achieve cell activation, proliferation, and differentiation [15]. Exposure to extremely low frequency electromagnetic fields (ELF-EMFs) has been shown to modulate the osteogenic differentiation of human bone marrow-multipotent stromal cells (hBM-MSCs) and was associated with increased alkaline phosphatase (ALP) levels and higher expression of osteogenesis-related genes in hBM-MSCs $[16,17]$. EMF application has also been proposed to treat bone fractures and has been used to slow bone matrix loss in animal experiments $[18,19]$. Several studies have demonstrated that EMFs enhance neuronal differentiation and cellular and molecular processes, such as neural marker expression [20-22].

Melanoblasts are neural crest-derived precursors of melanocytes, with the ability to produce melanin. They migrate to various parts of the body during the early stages of embryonic development before they become mature melanocytes. We hypothesize that EMFs may also activate melanocytes and increase melanogenesis, and the present study investigated frequency-dependent 
effects of EMFs on melanogenesis. Melanocytes were exposed to $30-75 \mathrm{~Hz}, 2 \mathrm{mT}$ EMFs for 3 days. Melanogenesis was measured in terms of melanin synthesis and tyrosinase activity, by western blotting, reverse transcription real-time quantitative polymerase chain reaction (RT-qPCR), and immunohistochemical staining.

\section{Result}

\subsection{Cell Proliferation and Mitochondrial Activity}

From the melanocyte strategic location in the basal layer of the epidermis, melanocytes communicate via their dendritic processes with 36-40 keratinocytes, to whom they transfer melanin-containing melanosomes [23]. Thus, the dendritic process is pivotal for skin melanocytes.

We used Helmholtz coils, comprising two identical circular coils (diameter $=40 \mathrm{~cm}$, distance $=15 \mathrm{~cm})$, and oriented to produce a region of nearly uniform rectangular pulse EMF $(\mathrm{Bm}=2 \mathrm{mT})$. The coils operated on alternating current, generating the PEMF. The coil current was controlled by a generator. The system was supplied by COMSOL 3.4 (COSMOL, Burlington, MA, USA) and a Tesla TM-701 meter (KANETEC, Tokyo, Japan) for monitoring magnetic flux density distribution. The culture dishes, multi-well plates, and multi-well plate cover slides were located in the center of the Helmholtz coils, as shown in Figure 1.
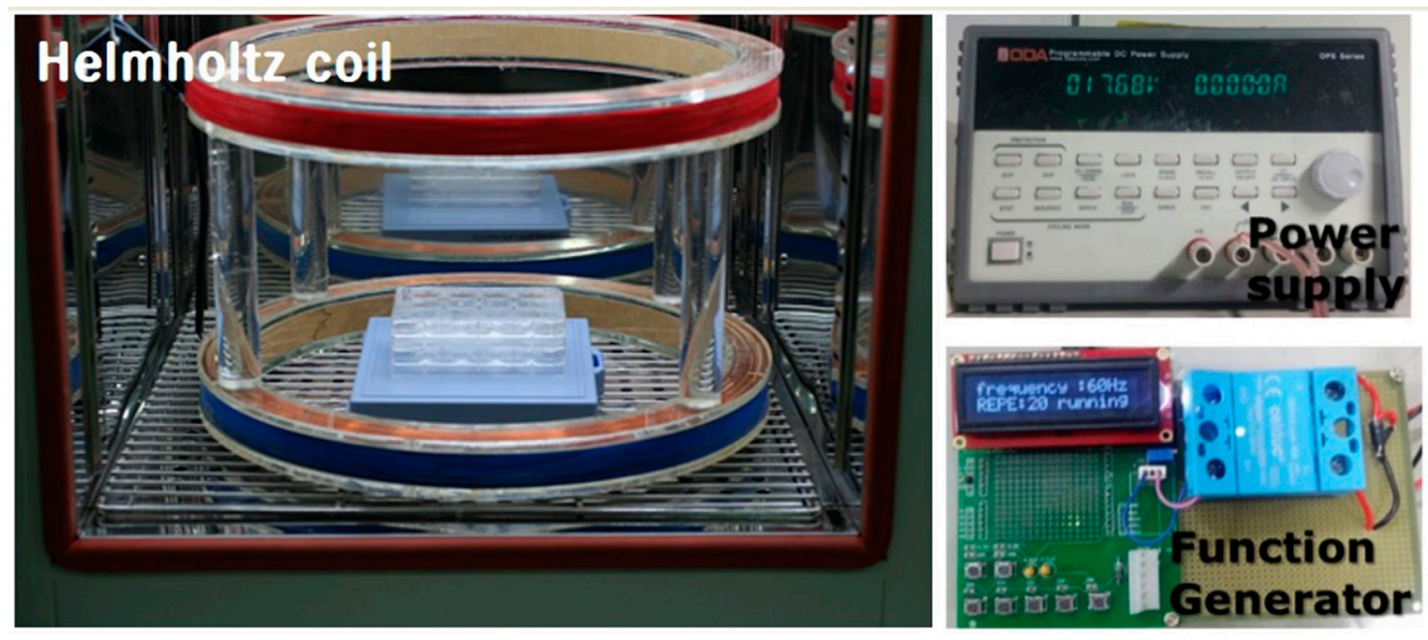

Figure 1. Photograph of the electromagnetic field (EMF) device. Pulsed EMF was generated using a pair of Helmholtz coils of $40 \mathrm{~cm}$ diameter and $15 \mathrm{~cm}$ separation.

Figure 2 shows the morphology of the melanocytes after $72 \mathrm{~h}$. Cells grown under control conditions and cells exposed to EMFs at $75 \mathrm{~Hz}$ showed characteristic bipolar dendritic processes, whereas cells exposed to EMFs at 50 and $60 \mathrm{~Hz}$ displayed highly branched dendritic networks and multipolar morphology (arrow). The number of dendritic networks and multipolar morphology was scored from observing a microscopy image (Table 1). Thus, exposure to ELF-EMFs at 50 and $60 \mathrm{~Hz}$ induced melanogenic maturation in the absence of chemical agents but did not trigger apoptosis or necrosis.

Table 1. The number of dendritic and multipolar cells $(n=4)$. (MSH: Melanocyte-stimulating hormone).

\begin{tabular}{ccccccc}
\hline Dendritic Cell Number & Control & MSH & $\mathbf{3 0 ~ H z}$ & $50 \mathbf{H z}$ & $\mathbf{6 0 ~ H z}$ & $\mathbf{7 5 ~ H z}$ \\
\hline multipolar morphology & $9 \pm 3$ & $16 \pm 3$ & $11 \pm 4$ & $25 \pm 4$ & $24 \pm 3$ & $18 \pm 4$ \\
\hline
\end{tabular}




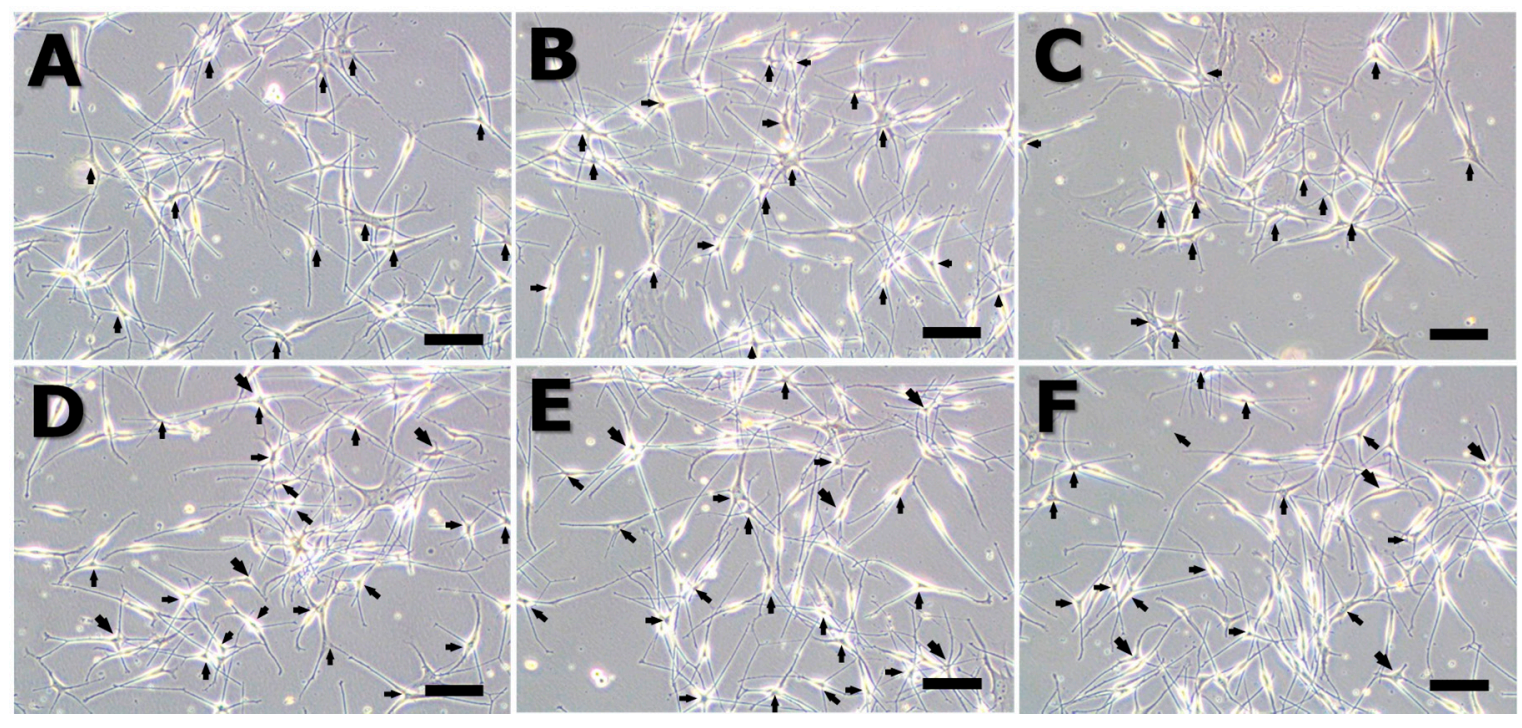

Figure 2. Melanocyte morphology after stimulation by an extremely low frequency electromagnetic field (ELF-EMF) for $72 \mathrm{~h}$. All groups were cultured in M254 media. Before ELF-EMF exposure, cells were cultured in modified M254 media containing forskolin, melanocyte-stimulating hormone $(\alpha-\mathrm{MSH})$, and 12-O-tetradecanoyl-phorbol-13-acetate for $72 \mathrm{~h}$. After culturing in differentiation media, cells were treated with continuous ELF-EMFs. The $\alpha$-MSH group was cultured in M254 media added to $5 \mathrm{nM} \alpha$-MSH. (A) control; (B) $\alpha-\mathrm{MSH}$; (C) $30 \mathrm{~Hz}$; (D) $50 \mathrm{~Hz}$; (E) $60 \mathrm{~Hz}$; and (F) $75 \mathrm{~Hz}$. Original magnification was $\times 100$; bar $=100 \mu \mathrm{m}$.

Cell count was approximately $6.4 \times 10^{4}$ for cells grown under control conditions, $6.5 \times 10^{4}$ for cells exposed to $\alpha$-MSH only, $6.4 \times 10^{4}$ for cells exposed to $30 \mathrm{~Hz}, 6.5 \times 10^{4}$ for cells exposed to $50 \mathrm{~Hz}$, $6.4 \times 10^{4}$ for cells exposed to $60 \mathrm{~Hz}$, and $6.5 \times 10^{4}$ for cells exposed to $75 \mathrm{~Hz}$. Thus, ELF-EMF exposure did not significantly affect cell proliferation (Figure $3 \mathrm{~A}$ ).
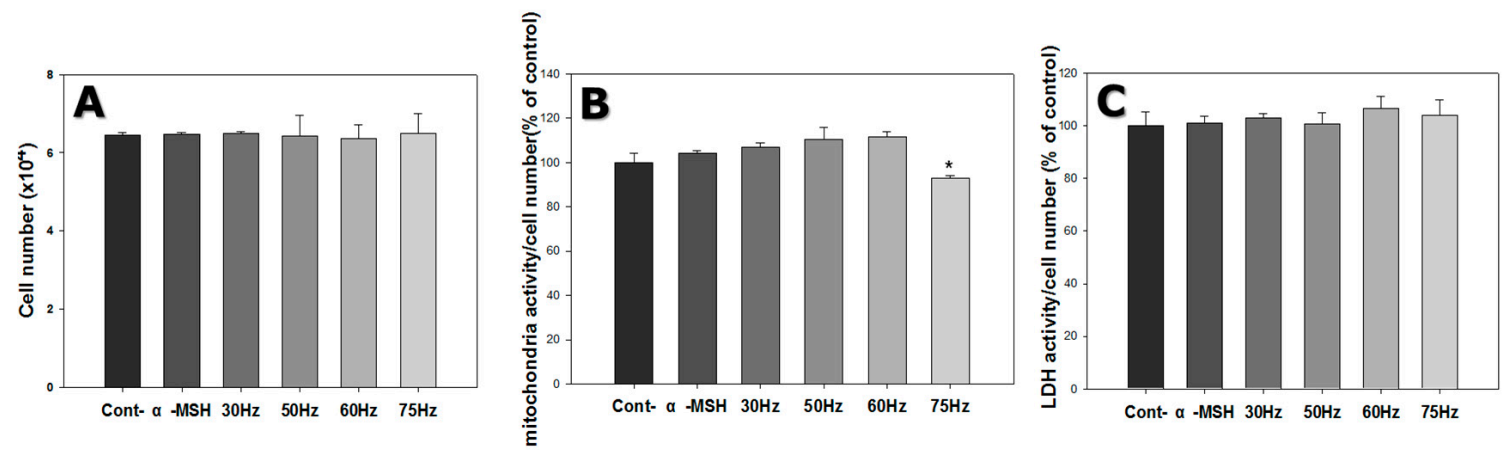

Figure 3. Cell proliferation, mitochondrial activity, and cytotoxicity of melanocytes after $72 \mathrm{~h}$ exposure to extremely low frequency electromagnetic fields. (A) Cell count (to measure cell proliferation); (B) 3-(4,5-dimethylthiazol-2-yl)-2,5-diphenyltetrazolium bromide assay (to determine cell mitochondrial activity); (C) Lactate dehydrogenase (LDH) assay (to examine cellular damage). Each bar represents mean \pm standard error from independent experiments performed in triplicate $(n=5) .{ }^{*} p<0.05$, compared to the control.

The mitochondrial activity of the cells was measured by the MTT assay. This method is based on the conversion of MTT into formazan crystals by living cells, which determines mitochondrial activity. Mitochondrial activity was evaluated by dividing the cell number by the measured mitochondrial activity. Mitochondrial activity per cell was similar for all ELF-EMF exposure cases, for most of the exposed group compared to the control (Figure 3B). 


\subsection{Cytotoxicity}

$\mathrm{LDH}$ is a cytoplasmic enzyme that catalyzes the reversible interconversion between pyruvic and lactic acid and is released when the cell membrane is damaged [24]. Hence, LDH is a convenient indicator of cellular injury or stress. Media were collected and analyzed after 3 days, to assess the condition of the cells. LDH activity was evaluated by dividing by the cell count (Figure 3C) and was similar for the 30, 50, 60 and $75 \mathrm{~Hz}$ groups compared to the control. Based on the LDH results in Figure 3C, the ELF-EMFs did not influence the damage to cell membranes.

\subsection{Melanin Content}

The amount of melanin in melanocytes was investigated by the melanin content assay, as shown in Figure 4A. Melanin content increased 1.1-fold on average, for cells exposed to ELF-EMFs. Melanin content of cells exposed to ELF-EMF at $50 \mathrm{~Hz}$ was 1.3 times the controls, and 1.1 times the cells exposed to $\alpha$-MSH only. Thus, ELF-EMFs induced increased melanogenesis.
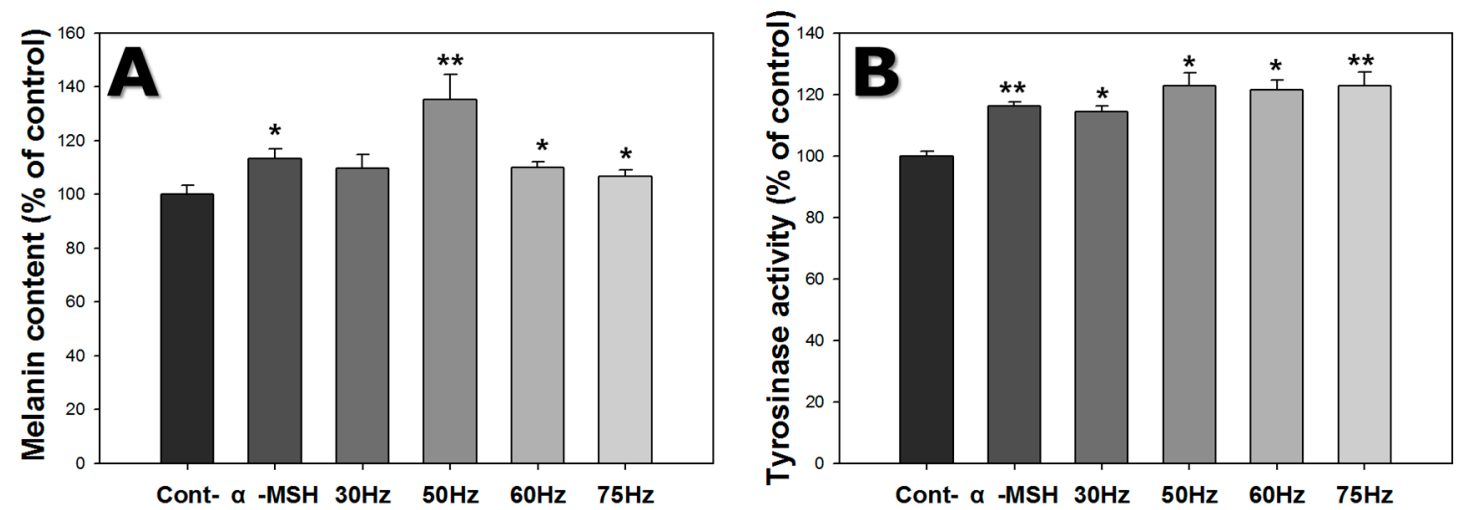

Figure 4. Effect of extremely low frequency electromagnetic fields (ELF-EMFs) on melanogenesis of melanocytes after exposed to ELF-EMFs for $72 \mathrm{~h}$. After ELF-EMFs exposure, melanin content and tyrosinase activity were determined. (A) Melanin content was detected by the melanin content assay; (B) Tyrosinase activity was measured by the tyrosinase assay. Each bar represents the mean \pm standard error of independent experiments performed in triplicate $(n=3) .{ }^{*} p<0.05,{ }^{* *} p<0.01$, compared to the control.

\subsection{Tyrosinase Activity}

Melanocyte tyrosinase activity was assessed using the tyrosinase activity assay, as shown in Figure 4B. Tyrosinase activity increased in cells exposed to ELF-EMFs. Cells exposed to 50 and $75 \mathrm{~Hz}$ were 1.2 times the controls, and 1.1 times those exposed to $\alpha$-MSH only. Therefore, ELF-EMF exposure increased tyrosinase activity.

\section{5. $R T-q P C R$}

The mRNA expression levels of key melanogenesis-related genes, such as tyrosinase and TRP-2, were measured at $72 \mathrm{~h}$, as shown in Figure 5. Tyrosinase mRNA levels in cells exposed to ELF-EMFs were on average 1.3-fold those in the controls. In particular, cells exposed to ELF-EMFs at 50 and $60 \mathrm{~Hz}$ showed tyrosinase expression 1.5 times the controls.

TRP-2 mRNA levels in cells exposed to ELF-EMFs were on average 2.0 times the controls. Cells exposed to $50 \mathrm{~Hz}$ showed elevated TRP-2 expression, at 2.5 times the controls. Consequently, ELF-EMF exposure stimulated the expression of melanogenesis-related mRNA species. 

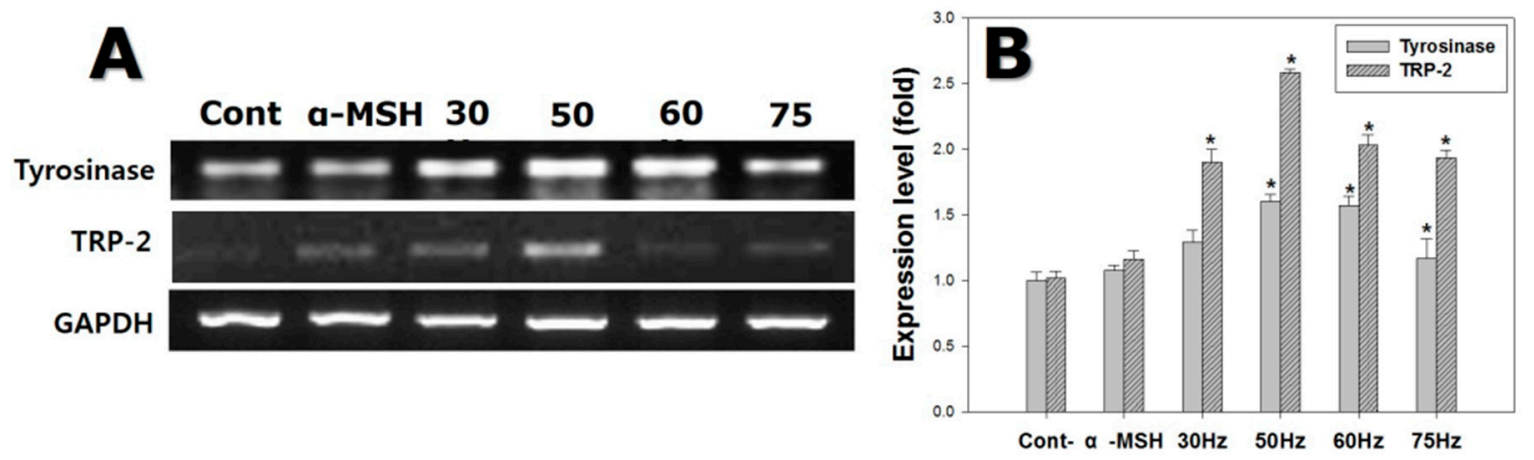

Figure 5. Gene expression detected by reverse transcription polymerase chain reaction (RT-PCR) on melanocytes after exposure to extremely low frequency electromagnetic fields for 72 h. (A) Electrophoretic RT-PCR for melanogenesis-related genes; (B) mRNA expression of melanogenesis-related genes, using glyceraldehyde-3-phosphate dehydrogenase (GAPDH) as the reference protein. Each bar represents the mean \pm standard error of independent experiments performed in triplicate $(n=5) .{ }^{*} p<0.05$, compared to the control (Cont).

\subsection{Western Blotting}

In order to study processes related to melanogenesis in melanocytes exposed to ELF-EMFs, we assessed the activation of $\mathrm{p}$-CREB and mitogen-activated protein kinases (MAPKs) signaling. CREB transcription factor p38 is involved in upregulation, while ERK and JNK pathways are involved in downregulation of melanogenesis. Figure 6 shows that p-CREB levels increased 1.2-fold in cells exposed to ELF-EMFs. More specifically, cells exposed to 50 and $75 \mathrm{~Hz}$ displayed high levels of p-CREB. p-ERK activation was reduced in cells exposed to ELF-EMFs, particularly those exposed to 50 and $60 \mathrm{~Hz}$. p-SAPK/JNK activation was also decreased in cells exposed to ELF-EMFs, mainly for cells exposed to 50 and $60 \mathrm{~Hz}$. Conversely, p-p38 activation was increased in cells exposed to ELF-EMFs, principally for the cells exposed to 50 and $60 \mathrm{~Hz}$ (Figure 7). Thus, ELF-EMF exposure stimulated melanogenesis.
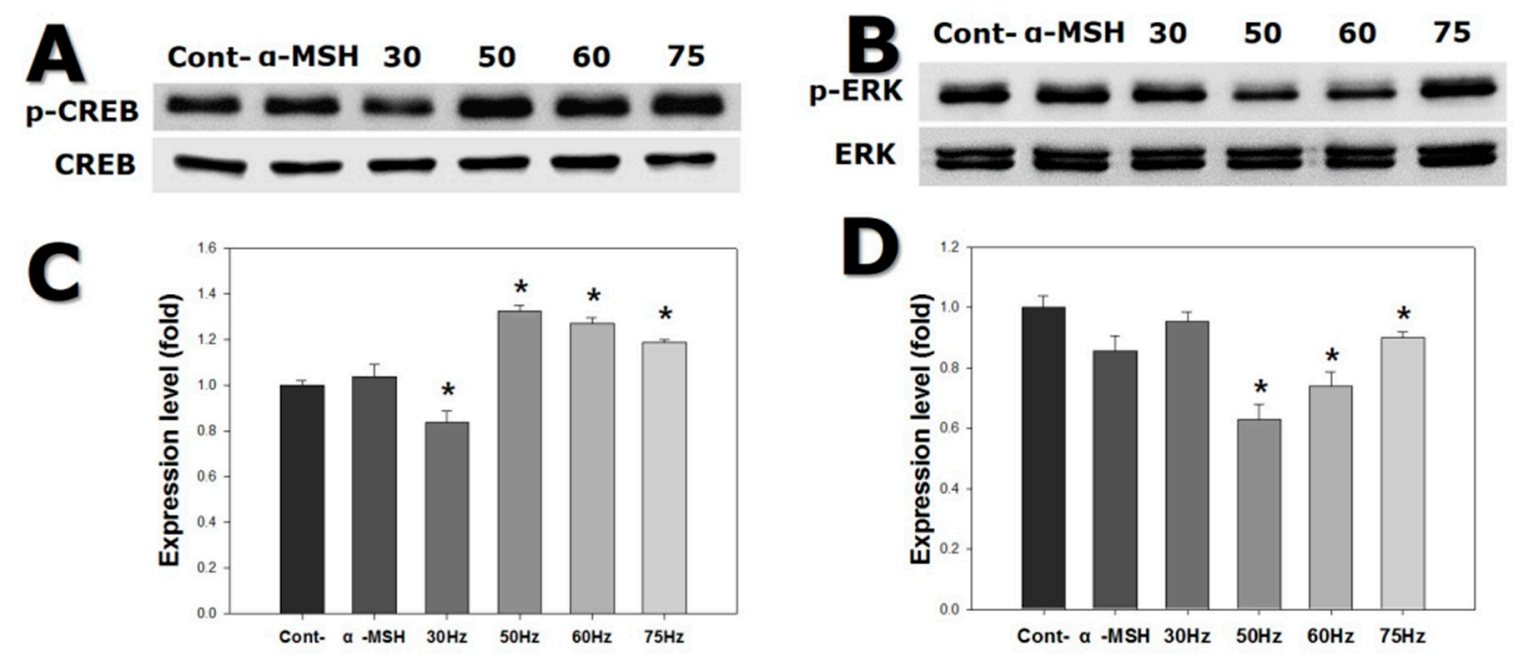

Figure 6. Western blot of cyclic adenosine monophosphate response element-binding protein (CREB) and extracellular signal-regulated kinase (ERK) expression in melanocytes after exposure to extremely low frequency electromagnetic fields for $72 \mathrm{~h}$. (A) CREB and phosphorylated-CREB (p-CREB) banding; (B) p-CREB expression; (C) ERK and phosphorylated ERK (p-ERK) expression; (D) p-ERK expression. Each bar represents the mean \pm standard error of independent experiments performed in triplicate $(n=5) .{ }^{*} p<0.05$, compared to the control (Cont). 

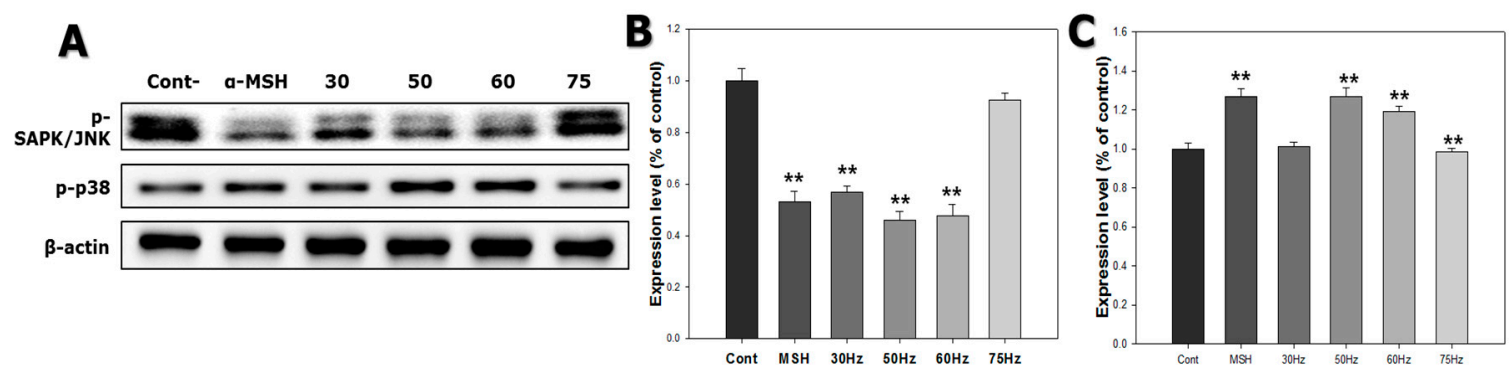

Figure 7. Western blot of stress-activated protein kinase/c-Jun N-terminal (SAPK/JNK) and p38 expression in melanocytes after exposure to extremely low frequency electromagnetic fields for $72 \mathrm{~h}$. (A) Phosphorylated-SAPK (p-SAPK)/JNK and phosphorylated-38 (p-p38) banding; (B) p-SAPK/JNK expression; (C) p-p38 expression. Each bar represents the mean \pm standard error of independent experiments performed in triplicate $(n=3)$. ${ }^{* *} p<0.01$, compared to the control (Cont).

Melanogenesis in melanocytes exposed to ELF-EMFs for $72 \mathrm{~h}$, was further investigated by quantifying the melanogenesis-related proteins after the exposure, with western blotting. Figure 8 shows that tyrosinase expression levels increased on average 2.0-fold in cells exposed to ELF-EMFs. Cells exposed to 50 and $60 \mathrm{~Hz}$ had strong tyrosinase upregulation compared to the controls.
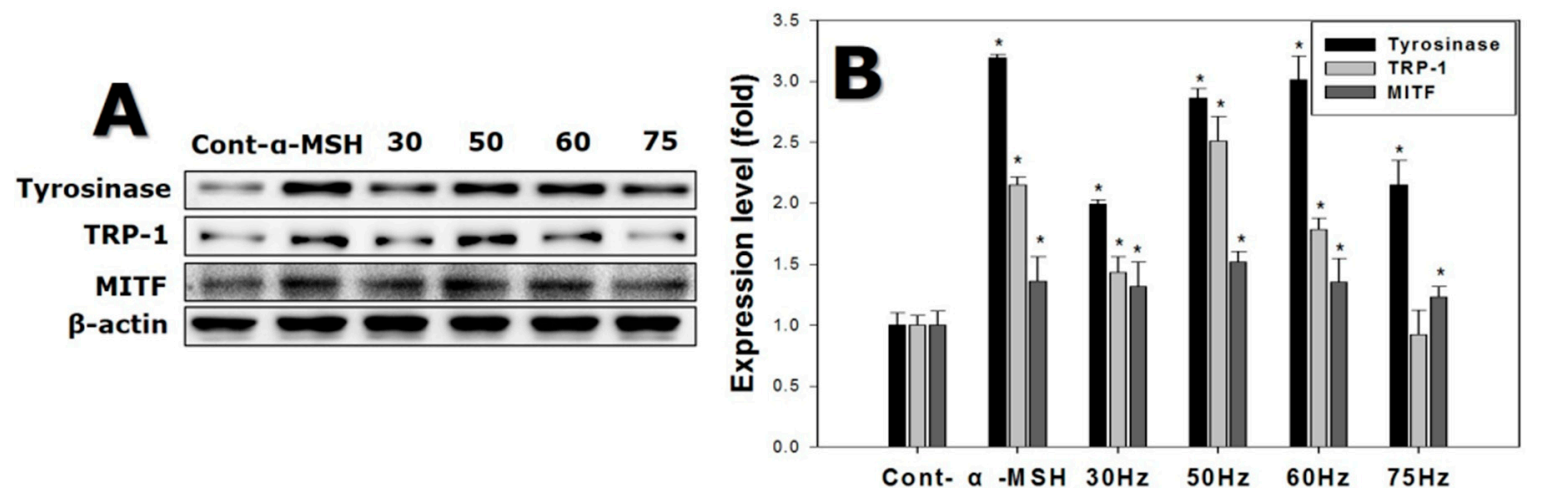

Figure 8. Western blot of protein expression levels detected in melanocytes after exposure to extremely low frequency electromagnetic fields for $72 \mathrm{~h}$. (A) Melanogenesis-related protein banding, using $\beta$-actin as an internal control; (B) Melanogenesis-related protein expression. Each bar represents the mean \pm standard error of independent experiments performed in triplicate $(n=5) .{ }^{*} p<0.05$, compared to the control (Cont).

TRP-1 expression levels were 2.5 times higher for cells exposed to ELF-EMFs than the control. Finally, cells exposed to 50 and $60 \mathrm{~Hz}$, expressed MITF more strongly, exhibiting expression levels 1.5 times greater than the controls.

\subsection{Immunohistochemistry}

Immunohistochemical staining was performed to assess the expression of proteinaceous markers of melanogenesis. HMB45 is a melanosome-specific antigen, and Melan-A is a melanocyte differentiation antigen. The relative staining intensity was evaluated by light microscopy, as shown in Table 2 and Figure 9. Compared to controls, both melanocyte-specific markers (HMB45, Melan-A) were strongly expressed in cells exposed to ELF-EMFs at 50 and $60 \mathrm{~Hz}$. 
Table 2. Relative staining intensity score for HMB45 and Melan-A.

\begin{tabular}{rcccccc}
\hline Marker & Control & MSH & $30 \mathbf{H z}$ & $50 \mathbf{H z}$ & $60 \mathrm{~Hz}$ & $\mathbf{7 5 ~ H z}$ \\
\hline HMB45 & + & ++ & + & +++ & +++ & ++ \\
Melan-A & + & ++ & + & +++ & +++ & ++ \\
\hline
\end{tabular}
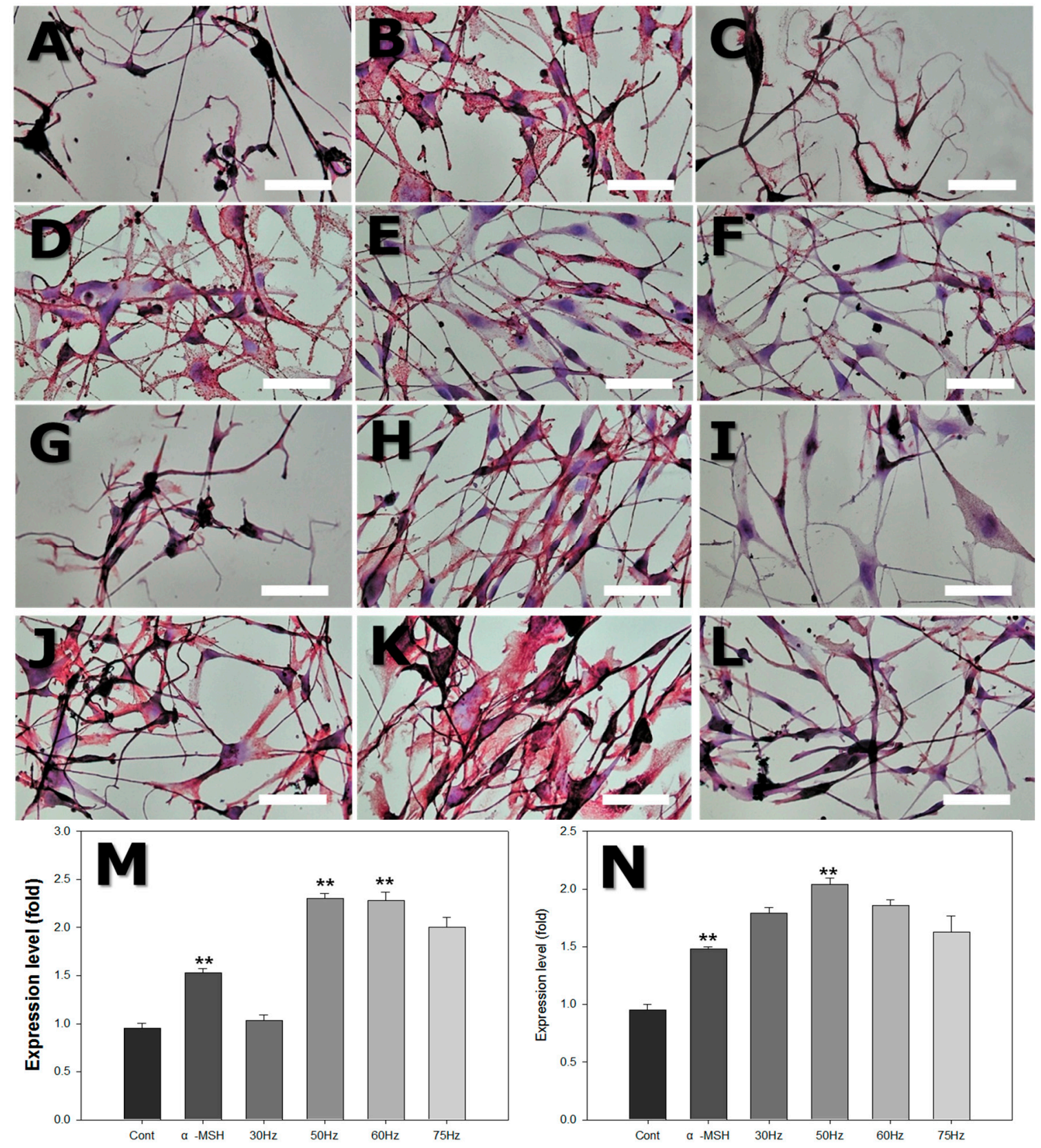

Figure 9. Light microscope photograph of human skin melanocytes attached to dish surface, stained with HMB45 and Melan-A after exposure to extremely low frequency electromagnetic field (ELF-EMF) for $72 \mathrm{~h}$. (A-F) with HMB45 staining: (A) Control (Cont); (B) alpha-melanocyte-stimulating hormone ( $\alpha$-MSH); (C) $30 \mathrm{~Hz}$; (D) $50 \mathrm{~Hz}$; (E) $60 \mathrm{~Hz}$; and (F) $75 \mathrm{~Hz}$. (G-L) with Melan-A staining: (G) Control; (H) $\alpha$-MSH; (I) $30 \mathrm{~Hz}$; (J) $50 \mathrm{~Hz}$; (K) $60 \mathrm{~Hz}$; and (L) $75 \mathrm{~Hz}$. Original magnification was $\times 400$; bar = $50 \mu \mathrm{m}$. Quantitative analysis of expression levels of HMB45 (M) and Melan-A (N) after ELF-EMFs exposure. Each bar represents the mean \pm standard error of independent experiments performed in triplicate $(n=4) .{ }^{* *} p<0.01$, compared to the control. 


\section{Discussion}

Melanin synthesis and pigment transfer to bulb keratinocytes are dependent on the availability of melanin precursors and regulation by signal transduction pathways intrinsic to skin and hair follicles, which are both receptor-dependent and -independent, act through auto-, para- or intracrine mechanisms and can be modified by hormonal. Some investigators have documented that signal transduction pathways involving SCF/c-Kit and ET1, ET3/ETA, and ETB play a crucial role in normal follicle melanogenesis. Also, many other researchers revealed that pro-pigmentary activity is initiated by binding of POMC-derived ACTH, $\alpha-\mathrm{MSH}$, and $\beta$-MSH peptides. Particularly the $\beta$-endorphin/ $\mu$-opiate receptor system also participates in the regulation of both human epidermal and follicular melanocyte biology, by inducing changes in dendricity, proliferation, and melanogenesis. Furthermore, it is well established that melatonin, interleukin- 1 and -6 , tumor necrosis factor- $\alpha$, transforming growth factor- $\beta$, interferon- $\gamma$, glucocorticoids, triiodothyronine, and dopaminergic and cholinergic agonists negatively regulate melanogenesis [7].

ELF-EMF interactions with biological systems and resultant health effects have been investigated, suggesting influences on numerous cell types and processes, including cell migration, differentiation, apoptosis, and stress responses [25,26]. Moreover, ELF-EMFs have been investigated regarding osteogenesis, bone healing, and neurogenesis, and the current authors have previously reported that ELF-EMFs promote neural differentiation of mesenchymal stem cells [27]. These above-mentioned studies suggest that ELF-EMF exposure affects cells through physical or mechanical effects on both intracellular and membrane proteins, including ion channels, membrane receptors, and enzymes [28]. However, previous research has not attempted to use ELF-EMFs to stimulate melanin synthesis in melanocytes.

The main purpose of this study was to confirm the effect of ELF-EMFs on melanogenesis and identify optimal conditions for ELF-EMF-induced melanogenesis in melanocytes. Frequency-dependent cytotoxicity of EMFs involved examination of cell morphology and the LDH assay results, which confirmed that the EMFs used in this study were not cytotoxic to melanocytes.

Melanocytes reside in the basal layer and produce the protective melanin pigment that is transferred to neighboring keratinocytes [4]. Melanin is synthesized by conversion of tyrosine into dopaquinone, catalyzed by tyrosinase, and the tyrosinase-related proteins TRP-1 and TRP- 2 are involved in this process. Therefore, to investigate the effects of EMFs on melanogenesis, we studied the activity of tyrosinase and the gene and protein expression of tyrosinase, TRP-1, and TRP-2. Tyrosinase is the key enzyme in melanin synthesis. TRP- 1 and TRP-2 share $40-45 \%$ amino acid identity with tyrosinase and are, likewise, critical for melanogenesis, functioning as downstream enzymes in the biosynthetic pathway $[29,30]$. Increased tyrosinase activity in melanocytes could be achieved by stimulation of tyrosinase gene expression, leading to higher levels of the corresponding protein in melanocytes.

Melanocyte tyrosinase activity increased after exposure to EMFs at $50-75 \mathrm{~Hz}$, as shown in Figure 4B, and PCR and western blot analysis confirmed that the expression of tyrosinase increased at both the gene and protein levels, after exposure to 50 and $60 \mathrm{~Hz}$. The expression of TRP-2 was significantly increased at $50 \mathrm{~Hz}$ (Figures 5 and 6).

The MITF transcription factor is a key regulator of melanocyte development, function, and survival by regulating genes involved in the cell cycle and melanocyte differentiation [31]. Activated MITF also raises protein levels, including tyrosinase, dopachrome tautomerase, TRP-1, as well as pigment production [32-34].

We investigated MITF protein expression level using western blotting. MITF protein expression increased with exposure to ELF-EMF at 50-60 Hz, which correlated with tyrosinase and TRP-1 expression. A previous study reported increased MITF and tyrosinase expression from physical stimulation of melanocytes [35]. The authors of that study demonstrated the effects of NB-UVB on the maturation of the melanocyte lineage differentiated from hair follicle-derived neural crest stem cells 
in vitro. NB-UVB increased the expression of MITF and tyrosinase during melanocytic differentiation and is currently used in clinical vitiligo phototherapy.

CREB is a basic leucine zipper (bZip) transcription factor, and p-CREB increases MITF expression [36]. Previously, the influence of aromatic-turmerone on inhibiting melanogenesis was suppressed by CREB activation, and expression of MITF, tyrosinase, TRP-1, and TRP-2 in B16F10 melanoma cells [37]. In contrast, it was reported that ginsenoside-induced melanogenesis, upregulated expression of MITF, tyrosinase, and p-CREB in human melanocytes [38]. Thus, increases in p-CREB expression are believed to increase melanogenesis. In the present study, western blotting analysis verified that expression of $\mathrm{p}$-CREB stimulated melanogenesis in human melanocytes exposed to ELF-EMFs.

The ERK pathway is a key signaling pathway involved in controlling cell growth. ERK activation also increases cell proliferation in a variety of cell types [39]. The ERK pathway is a major signaling cascade, participating in many signal transduction processes, and is involved in regulating MITF [40]. ERK activation leads to phosphorylation of MITF, which results in decreased melanin synthesis by melanocytes [37]. ERK is one of the MAPK family, which includes JNK and p38.

Similar to ERK activation, SAPK/JNK activation is also related to downregulation of melanogenesis. In contrast, p38 activation increases melanogenesis by stimulating expression of MITF and tyrosinase transcription [41-43]. Shogaol inhibits $\alpha$-MSH-induced melanogenesis by accelerating the ERK and PI3k/serine-threonine kinase (Akt) pathways in B16F10 melanoma cells [44] and was also found to downregulate MITF expression. Ascorbic acid stimulates melanogenesis in B16F10 murine melanoma cells by expression of MITF, tyrosinase, TRP-1, and TRP-2, as well as activation of the MAPK family, accelerates p38 activation and suppresses activation of JNK and ERK [41]. Consequently, increased p-ERK and p-SAPK/JNK expression are believed to decrease melanogenesis, whereas p-ERK and p-SAPK/JNK downregulation increases melanogenesis. According to the western blotting analysis results of the current study, human melanocytes exposed to EMFs at 50 and $60 \mathrm{~Hz}$, increased melanogenesis in association with p-ERK and p-SAPK/JNK downregulation and p38 upregulation.

HMB-45 is an antigen that appears in adult melanocytes during stimulation and in fetal skin, as well as in melanomas [45]. Melan-A has also been identified as a melanocytic differentiation marker, which is recognized as an antigen on melanoma cells, by cytotoxic T-lymphocytes [46]. In the current study, melanocytes stained strongly positively for HMB- 45 and Melan-A, when exposed to $\alpha$-MSH or ELF-EMFs at 50-60 Hz. Hence, ELF-EMFs at these frequencies can activate melanocytes and stimulate melanin synthesis.

In summary, the present study shows that melanogenesis can be stimulated by exposure to ELF-EMFs.

\section{Materials and Methods}

\subsection{Cell Culture}

QualiCell ${ }^{\circledR}$ human melanoblast stem cells (Creative Bioarray, New York, NY, USA) were maintained in culture in Medium 254 (M254, Invitrogen, Waltham, MA, USA) with propidium monoazide-free human melanocyte growth supplement (HMGS-2, Invitrogen) in an incubator with $5 \%$ humidified atmosphere at $37^{\circ} \mathrm{C}$. Melanoblasts from passages 3 to 7 were used for experiments. The medium was changed every 2-3 days. For subculture, cells were washed with phosphate buffered saline (PBS), detached with Accutase (Innovative Cell Tech., San Diego, CA, USA), and passaged at a plate 1:3 plate ratio when the cells reached $80-90 \%$ confluence.

Melanoblasts were cultured in melanocyte differentiation medium, to produce melanocytes. The differentiation medium consisted of M254, HMGS-2, $10 \mathrm{nM} \alpha$-MSH (Sigma Aldrich, St. Louise, MO, USA), $10 \mathrm{nM}$ 12-O-tetradecanoyl-phorbol-13-acetate (TPA; Sigma Aldrich), and $20 \mu \mathrm{M}$ forskolin (Sigma Aldrich). Experiments progressed once the melanoblasts had been treated with the differentiation medium for 3 days when the medium was replaced with M254 medium, and the cells were exposed to ELF-EMFs. 


\subsection{Exposure to Extremely Low Frequency Electromagnetic Fields (ELF-EMFs)}

We used pulsed ELF-EMFs $(2 \mathrm{mT}$, for $30,50,60$, and $75 \mathrm{~Hz})$ and the coils were placed in a $37^{\circ} \mathrm{C}$, $5 \% \mathrm{CO}_{2}$ incubator. Cells were exposed to EMFs for $72 \mathrm{~h}$. The stimulus waveform was pulse type, with $0.25 \mu$ s duration and $20 \mathrm{G}(2 \mathrm{mT})$ intensity. Control cultures were located in a separate incubator to avoid ELF-EMF exposure, and the control media were identical to the experimental cell cultures.

ELF-EMF exposure was performed in the following order. Melanoblasts were seeded in a 6-well plate or on a coverslip in a multi-well plate and cultured with melanocyte induction media for 3 days. The media were then changed to melanocyte culture media M254, and either exposed to the ELF-EMF or $5 \mathrm{nM}$ MSH was added (control group).

\subsection{Cell Proliferation Measurement and Mitochondrial Activity Assay}

For cell proliferation and 3-(4,5-dimethylthiazol-2-yl)-2,5-diphenyltetrazolium bromide assay (MTT) assay, cells were seeded at $1 \times 10^{4}$ cells per well in six-well plates and cultured with melanocyte differentiation media for 3 days. After induction of differentiation, ELF-EMF exposure was performed for $72 \mathrm{~h}$.

A cell counter was used to measure cell proliferation $\left(\right.$ Scepter $^{\mathrm{TM}}$, Millipore Corporation, Billerica, MA, USA) and cell activity was assessed by the MTT assay, a colorimetric assay for measuring cell metabolic activity.

For the MTT assay, each well was treated with MTT solution ( $5 \mathrm{mg} / \mathrm{mL}$, Sigma Aldrich), and the plates were incubated at $37^{\circ} \mathrm{C}$ for $1.5 \mathrm{~h}$. The solution was then replaced with dimethyl sulfoxide (DMSO), to dissolve the formazan, and shaken for $5 \mathrm{~min}$. The absorbance of the resulting solution was measured at $570 \mathrm{~nm}$.

\subsection{Cytotoxicity Assay}

Cytotoxicity was evaluated by the lactate dehydrogenase (LDH) assay. For the LDH assay, cells were seeded at $1 \times 10^{4}$ cells per well in six-well plates and cultured with melanocyte differentiation media for 3 days. After induction of differentiation, ELF-EMF exposure was performed for $72 \mathrm{~h}$.

The cultured media was then collected, and an LDH-LQ kit was used (Asan Pharmaceutical, Seoul, Korea). The cultured medium $(100 \mu \mathrm{L})$ was placed in a 96 -well plate, $50 \mu \mathrm{L}$ of working solution was added, and the plates then incubated at room temperature for $30 \mathrm{~min}$. The reaction was terminated with $50 \mu \mathrm{L}$ of stop solution $(1 \mathrm{~N} \mathrm{HCl})$. Absorbance was measured at $490 \mathrm{~nm}$.

\subsection{Melanin Content Assay}

The melanin content of cultured melanocytes exposed to ELF-EMFs was determined using a modified method of a previously published approach [47]. Cells were seeded at $1 \times 10^{4}$ cells per well in six-well plates. After removing the culture medium from the plates, the cells were solubilized with $10 \%$ DMSO dissolved in $1 \mathrm{M} \mathrm{NaOH}$ and boiled at $80{ }^{\circ} \mathrm{C}$ for $2 \mathrm{~h}$. Next, the cells were centrifuged at 15,000 rpm for $15 \mathrm{~min}$ and the supernatant extracted. The melanin content of the supernatant was measured using an enzyme-linked immunosorbent assay (ELISA) plate reader at $405 \mathrm{~nm}$ (Spectrum Analyzer. Victor 1420-050, PerkinElmer Life Science, Turku, Finland).

\subsection{Tyrosinase Activity Assay}

For measurement of the intracellular tyrosinase activity, we slightly modified a previously described method [23]. Melanoblasts were seeded at $1 \times 10^{4}$ cells per well in six-well plates. After removing the culture medium, the cells were washed with PBS and lysed with 10\% Triton X-100 (Sigma Aldrich). Cells were then harvested, centrifuged at 15,000 rpm for $15 \mathrm{~min}$, and the supernatant extracted. We performed a bicinchoninic acid (BCA) assay (Thermo Fisher Scientific, Rockford, IL, USA) on the supernatant to measure protein levels, using bovine serum albumin (BSA) as a standard, adjusted to the same concentration as the sample protein with lysis buffer. L-DOPA (Sigma Aldrich, 
St. Louise, MO, USA) in sodium phosphate buffer $(10 \mathrm{mM})$ was added, followed by incubation at $37^{\circ} \mathrm{C}$ for $30 \mathrm{~min}$. Absorbance was measured at $475 \mathrm{~nm}$, with an ELISA plate reader (Spectrum Analyzer. Victor 1420-050, PerkinElmer Life Science).

\section{7. $R T-q P C R$}

Total cellular RNA was isolated using $500 \mu \mathrm{L}$ of TRIzol reagent (Invitrogen). Samples were added to $100 \mu \mathrm{L}$ of chloroform (Sigma Aldrich), followed by vortexing, and incubation at room temperature for $3 \mathrm{~min}$. After centrifuging at 12,000 rpm at $4{ }^{\circ} \mathrm{C}$ for $15 \mathrm{~min}$, the upper supernatant was transferred to empty tubes, and $500 \mu \mathrm{L}$ of isopropanol was added. After mixing and incubation for at room temperature for $10 \mathrm{~min}$, the solution was centrifuged at $14,000 \mathrm{rpm}$ at $4{ }^{\circ} \mathrm{C}$ for $10 \mathrm{~min}$. The supernatant, without pellets, was removed and added to $1 \mathrm{~mL}$ of $70 \%$ ethanol. After centrifuging at $9000 \mathrm{rpm}$ at $4{ }^{\circ} \mathrm{C}$ for $5 \mathrm{~min}$, the supernatant was discarded, and the pellets were dried at room temperature. The dry pellets were added to $20 \mu \mathrm{L}$ of diethylpyrocarbonate (DEPC)-water and placed on ice.

Total RNA concentration was measured using a Nanodrop device (Thermo Fisher Scientific). A reverse transcriptase (RT) reaction from an Advantage RT-PCR kit (Clontech, Palo Alto, CA, USA) was used to synthesize cDNA from $2 \mu \mathrm{g}$ of total RNA, following the manufacturer's protocols. RT-PCR primers were purchased from Bioneer (Taejon, Korea). Tyrosinase and tyrosinase-related protein 2 (TRP-2) were quantified, and the corresponding primer sequences are listed in Table 3. Band images were obtained with Molecular Imager ChemiDoc XRS+ (Bio-Rad, Hercules, CA, USA). ImageJ software (National Institutes of Health, Bethesda, MD, USA) was used for quantitative analysis of the RT-PCR from digitized band pictures.

Table 3. Primers used for reverse transcription real-time quantitative polymerase chain reaction.

\begin{tabular}{ccc}
\hline Gene & Upstream Primer Sequence & Downstream Primer Sequence \\
\hline $\begin{array}{c}\text { Glyceraldehyde-3-phosphate } \\
\text { dehydrogenase }\end{array}$ & $5^{\prime}$-ACC ACA GTC CAT GCC ATC AC-3' & $5^{\prime}$-TCC ACC CTG TTG CTG TA-3' \\
\hline Tyrosinase & $5^{\prime}$-CTC AAA GCA TGC ACA AT-3' & $5^{\prime}$-GCC CAG ATC TTT GGA TGA AA-3' \\
\hline Tyrosinase-related protein 2 & $5^{\prime}$-TTC GGC AGA ACA TCC ATT CC-3' & $5^{\prime}$-TTG GCA ATT TCA TGC TGT TTC-3' \\
\hline
\end{tabular}

\subsection{Western Blotting}

Cells were lysed in sample buffer consisting of $2 \%$ sodium dodecyl sulfate (SDS), $5 \%$ 2-mercaptoethanol, $10 \%$ glycerol, and $0.1 \mathrm{mg} / \mathrm{mL}$ bromophenol blue in Tris- $\mathrm{HCl}, \mathrm{pH}$ 6.8, by boiling at $100{ }^{\circ} \mathrm{C}$ for $5 \mathrm{~min}$. A BCA assay was performed, with BSA as a standard, to ensure loading of identical protein amounts in the dodecyl sulfate-polyacrylamide gel electrophoresis (SDS-PAGE). Then, $30 \mu \mathrm{g}$ of the lysed protein was electrophorized by $10 \%$ SDS-PAGE and transferred onto a nitrocellulose membrane. The membranes were blocked with 5\% skim milk and washed trice in Tris-buffered saline-Tween 20 (TBS-T) for $15 \mathrm{~min}$. Membranes were then incubated with primary antibodies for $\beta$-actin (Sigma Aldrich), tyrosinase, tyrosinase-related protein 1 (TRP-1), microphthalmia-associated transcription factor (MITF) (Santa Cruz, CA, USA), extracellular signal-regulated kinase (ERK), p-ERK, CREB, p-CREB, p-p38, phosphorylated stress-activated protein kinase/c-Jun N-terminal kinase (p-SAPK/JNK) (Cell Signaling) diluted in TBS-T containing 5\% BSA, 0.05\% sodium azide at $4{ }^{\circ} \mathrm{C}$ overnight. After washing with TBS-T, the membranes were incubated with horseradish peroxidase-conjugated secondary antibodies, such as anti-rabbit, anti-mouse (Cell Signaling) and anti-goat (Santa Cruz) immunoglobulin G diluted in 5\% skim milk in TBS-T. Band images were obtained by using an electrogenerated chemiluminescence system (Thermo Fisher Scientific) and Molecular Imager ChemiDoc XRS+ (Bio-Rad, Hercules, CA, USA). ImageJ software (National Institutes of Health, Bethesda, MD, USA) allowed quantitative analysis of western blotting using digitized band images. 


\subsection{Immunohistochemistry}

For immunohistochemistry analysis, coverslips were placed in a 24-well plate, and then cells were seeded directly on the coverslips. After exposure to ELF-EMF, cells were cultured on a coverslip then fixed by incubation in $4 \%$ paraformaldehyde at $4{ }^{\circ} \mathrm{C}$ for $20 \mathrm{~min}$. Fixed cells were incubated with anti-HMB45 and anti-Melan-A (Abcam, Cambridge, UK, at 1:1000 dilution). Localization of HMB45 and Melan-A was determined using an avidin-immunoalkaline phosphatase method, with vector red as the red chromogen product. Relative staining intensity was scored arbitrarily according to intensities in a light microscopy image, as follows: no or weak staining $(-)$, low intensity $(+)$, moderate intensity $(++)$, and strong intensity $(+++)$. The staining intensity was analyzed with ImageJ software (National Institutes of Health) for the quantitative immunohistochemistry analysis.

\subsection{Statistical Analysis}

Results are reported as the mean \pm standard error (SE), and each experiment was repeated at least in triplicate. Data were analyzed by one-way analysis of variance (ANOVA) and Student's $t$-test. Difference between means was considered significant when $p<0.05\left({ }^{*} p<0.05,{ }^{* *} p<0.01\right)$. Graphical representations were produced with Sigmaplot 2001 software (Systat Software Inc., San Jose, CA, USA)

\section{Conclusions}

We have demonstrated that ELF-EMFs can induce melanogenesis in melanocytes. Exposure to ELF-EMFs was associated with increases in the level of p-CREB and p-p38, also inhibited of phosphorylated extracellular signal-regulated protein kinase and phosphorylated stress-activated protein kinase/c-Jun N-terminal kinase. As a results, MITF was upregulated and it's upregulation enhances the expression of the melanogenesis-related genes tyrosinase, TRP-1, and TRP-2, and stimulates melanin synthesis at $50 \mathrm{~Hz}$ (Figure 10).

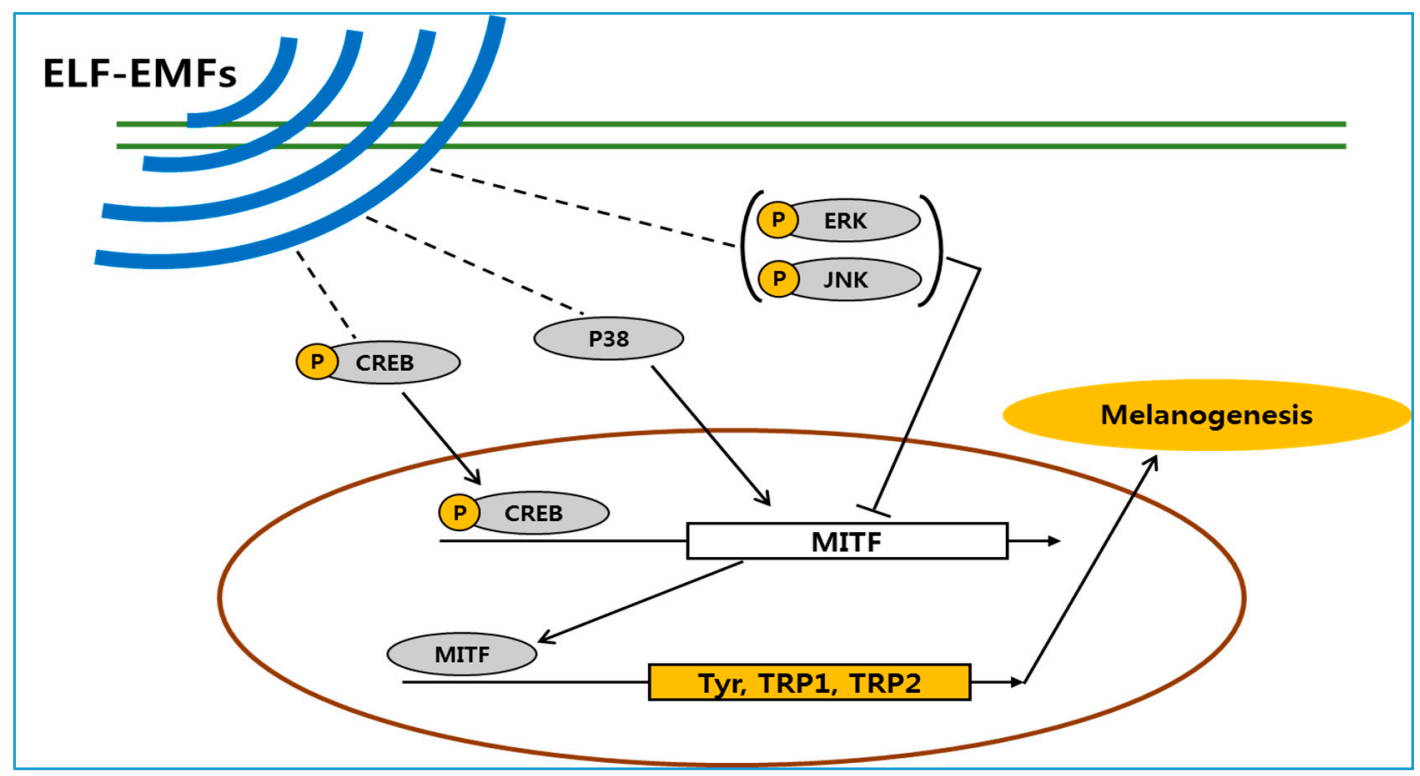

Figure 10. The proposed mechanism by which an extremely low frequency electromagnetic field (ELF-EMF) induces melanin biosynthesis. Schematic shows that ELF-EMFs increases expression of microphthalmia-associated transcription factor (MITF) in human melanocytes. (p-CREB: phosphorylated cAMP response element-binding protein, p38: protein 38kDa, p-JNK: phosphorylated c-Jun N-terminal kinase, p-ERK: phosphorylated extracellular signal-regulated protein kinase, MITF microphthalmia-associated transcription factor, Tyr: tyrosinase, TRP: tyrosinase-related protein) 
EMFs are non-invasive and non-toxic, but they interact with biological systems and have health effects. The results of this work may be applicable for gray hair treatment or therapeutically, for inducing repigmentation in the skin of vitiligo patients.

Future studies will focus on EMF-induced melanogenesis in a three-dimensional culture model and in vivo.

Acknowledgments: Grant sponsor: Korean Health Technology R\&D Project, Ministry of Health \& Welfare, Republic of Korea, Grant: HN14C0086.

Author Contributions: Young-Kwon Seo conceived and designed experiments; Yu-Mi Kim and Sang-Eun Cho performed experiments and analyzed the data; Soo-Chan Kim contributed devices of electromagnetic field; Yu-Mi Kim, Hyun-Joon Jang and Young-Kwon Seo wrote the paper.

Conflicts of Interest: The authors declare no conflict of interest.

\section{References}

1. Videira, I.F.; Moura, D.F.; Magina, S. Mechanisms regulating melanogenesis. Anais Bras Dermatol. 2013, 88, 76-83. [CrossRef]

2. Brenner, M.; Hearing, V.J. The protective role of melanin against UV damage in human skin. Photochem. Photobiol. 2008, 84, 539-549. [CrossRef] [PubMed]

3. Slominski, A.; Wortsman, J.; Luger, T.; Paus, R.; Solomon, S. Corticotropin Releasing Hormone and Proopiomelanocortin Involvement in the Cutaneous Response to Stress. Physiol. Rev. 2000, 80, 979-1010. [PubMed]

4. Slominski, A.T.; Zmijewski, M.A.; Zbytek, B.; Tobin, D.J.; Theoharides, T.C.; Rivier, J. Key role of CRF in the skin stress response system. Endocr. Rev. 2013, 34, 827-884. [CrossRef] [PubMed]

5. Slominski, A.; Tobin, D.J.; Shibahara, S.; Wortsman, J. Melanin Pigmentation in Mammalian Skin and Its Hormonal Regulation. Physiol. Rev. 2004, 84, 1155-1228. [CrossRef] [PubMed]

6. Slominski, A.; Zmijewski, M.A.; Pawelek, J. L-tyrosine and L-dihydroxyphenylalanine as hormone-like regulators of melanocyte functions. Pigment Cell Melanoma Res. 2011, 25, 14-27. [CrossRef] [PubMed]

7. Slominski, A.; Wortsman, J.; Plonka, P.M.; Schallreuter, K.U.; Paus, R.; Tobin, D.J. Hair follicle pigmentation. J. Investig. Dermatol. 2005, 124, 13-21. [CrossRef] [PubMed]

8. Endou, M.; Aoki, H. Prevention of hair graying by factors that promote the growth and differentiation of melanocytes. J. Dermatol. 2014, 41, 716-723. [CrossRef] [PubMed]

9. Nath, S.K.; Majumder, P.P.; Nordlund, J.J. Genetic epidemiology of vitiligo: Multilocus recessivity cross-validated. Am. J. Hum. Genet. 1994, 55, 981-990. [PubMed]

10. Halder, R.M.; Chappell, J.L. Vitiligo update. Semin. Cutan. Med. Surg. 2009, 28, 86-92. [CrossRef] [PubMed]

11. Namazi, M.R. Neurogenic dysregulation, oxidative stress, autoimmunity, and melanocytorrhagy in vitiligo: Can they be interconnected? Pigment Cell Melanoma Res. 2007, 20, 360-363. [CrossRef] [PubMed]

12. Yazdani Abyaneh, M.; Griffith, R.D. Narrowband ultraviolet B phototherapy in combination with other therapies for vitiligo: Mechanisms and efficacies. J. Eur. Acad. Dermatol. Venereol. 2014, 28, 1610-1622. [CrossRef] [PubMed]

13. Avci, P.; Gupta, A. Low-level laser (light) therapy (LLLT) in skin: Stimulating, healing, restoring. Semin. Cutan. Med. Surg. 2013, 32, 41-52. [PubMed]

14. Lan, C.C.; Wu, C.S.; Chiou, M.H.; Chiang, T.Y.; Yu, H.S. Low-energy helium-neon laser induces melanocyte proliferation via interaction with type IV collagen: Visible light as a therapeutic option for vitiligo. Br. J. Dermatol. 2009, 161, 273-280. [CrossRef] [PubMed]

15. Lacy-Hulbert, A.; Metcalfe, J.C.; Hesketh, R. Biological responses to electromagnetic fields. FASEB J. 1998, 12, 395-420. [PubMed]

16. Tsai, M.T.; Li, W.J.; Tuan, R.S.; Chang, W.H. Modulation of osteogenesis in human mesenchymal stem cells by specific pulsed electromagnetic field stimulation. J. Orthop. Res. 2009, 27, 1169-1174. [CrossRef] [PubMed]

17. Sun, L.Y.; Hsieh, D.K.; Lin, P.C.; Chiu, H.T.; Chiou, T.W. Pulsed electromagnetic fields accelerate proliferation and osteogenic gene expression in human bone marrow mesenchymal stem cells during osteogenic differentiation. Bioelectromagnetics 2010, 31, 209-219. [CrossRef] [PubMed] 
18. Sert, C.; Mustafa, D.; Düz, M.Z.; Akşen, F.; Kaya, A. The preventive effect on bone loss of 50-Hz, 1-mT electromagnetic field in ovariectomized rats. J. Bone Mine Metab. 2002, 20, 345-349. [CrossRef] [PubMed]

19. McLeod, K.J.; Rubin, C.T. The effect of low-frequency electrical fields on osteogenesis. J. Bone Jt. Surg. 1992, 74, 920-929. [CrossRef]

20. Piacentini, R.; Ripoli, C.; Mezzogori, D.; Azzena, G.B.; Grassi, C. Extremely low frequency electromagnetic fields promote in vitro neurogenesis via upregulation of $\mathrm{Ca}(\mathrm{v}) 1$-channel activity. J. Cell Physiol. 2008, 215, 129-139. [CrossRef] [PubMed]

21. Cuccurazzu, B.; Leone, L.; Podda, M.V.; Piacentini, R.; Riccardi, E.; Ripoli, C.; Azzena, G.B.; Grassi, C. Exposure to extremely low-frequency $(50 \mathrm{~Hz})$ electromagnetic fields enhances adult hippocampal neurogenesis in C57BL/6 mice. Exp. Neurol. 2010, 226, 173-182. [CrossRef] [PubMed]

22. Cho, H.; Seo, Y.K.; Yoon, H.H.; Kim, S.C.; Kim, S.M.; Song, K.Y.; Park, J.K. Neural stimulation on human bone marrow-derived mesenchymal stem cells by extremely low frequency electromagnetic fields. Biotechnol. Prog. 2012, 28, 1329-1335. [CrossRef] [PubMed]

23. Slominski, A.; Paus, R.; Schadendorf, D. melanocyte as "sensory" and regulatory cells in the epidermis. J. Theor. Biol. 1993, 164, 103-120. [CrossRef] [PubMed]

24. Mitchell, D.B.; Santone, K.S.; Acosta, D. Evaluation of cyto $\neg$ toxicity in cultured cells by enzyme leakage. Methods Cell Sci. 1980, 6, 113-116.

25. Naarala, J.; Hoyto, A.; Markkanen, A. Cellular effects of electromagnetic fields. Altern. Lab. Anim. 2004, 32, 355-360. [PubMed]

26. Seeliger, C.; Falldorf, K.; Sachtleben, J.; van Griensven, M. Low-frequency pulsed electromagnetic fields significantly improve time of closure and proliferation of human tendon fibroblasts. Eur. J. Med. Res. 2014, 19, 37. [CrossRef] [PubMed]

27. Leone, L.; Podda, M.V.; Grassi, C. Impact of electromagnetic fields on stem cells: Common mechanisms at the crossroad between adult neurogenesis and osteogenesis. Front. Cell Neurosci. 2015, 9, 228. [CrossRef] [PubMed]

28. D'Angelo, C.; Costantini, E.; Kamal, M.A.; Reale, M. Experimental model for ELF-EMF exposure: Concern for human health. Saudi J. Biol. Sci. 2015, 22, 75-84. [CrossRef] [PubMed]

29. Botchkareva, N.V.; Khlgatian, M.; Longley, B.J.; Botchkarev, V.A.; Gilchrest, B.A. SCF/c-kit signaling is required for cyclic regeneration of the hair pigmentation unit. FASEB J. 2001, 15, 645-658. [CrossRef] [PubMed]

30. Winder, A.; Kobayashi, T.; Tsukamoto, K.; Urabe, K.; Aroca, P.; Kameyama, K.; Hearing, V.J. The tyrosinase gene family: Interactions of melanogenic proteins to regulate melanogenesis. Cell. Mol. Biol. Res. 1994, 40, 613-626. [PubMed]

31. Hemesath, T.J.; Price, E.R.; Takemoto, C.; Badalian, T.; Fisher, D.E. MAP kinase links the transcription factor Microphthalmia to c-Kit signalling in melanocytes. Nature 1998, 391, 298-301. [PubMed]

32. Abdel-Malek, Z.; Swope, V.B.; Suzuki, I.; Akcali, C.; Harriger, M.D.; Boyce, S.T.; Urabe, K.; Hearing, V.J. Mitogenic and melanogenic stimulation of normal human melanocytes by melanotropic peptides. Proc. Natl. Acad. Sci. USA 1995, 92, 1789-1793. [CrossRef] [PubMed]

33. Hunt, G.; Todd, C.; Cresswell, J.E.; Thody, A.J. Alpha-melanocyte stimulating hormone and its analogue Nle4DPhe7 alpha-MSH affect morphology, tyrosinase activity and melanogenesis in cultured human melanocytes. J. Cell Sci. 1994, 107, 205-211. [PubMed]

34. Suzuki, I.; Cone, R.D.; Im, S.; Nordlund, J.; Abdel-Malek, Z.A. Binding of melanotropic hormones to the melanocortin receptor MC1R on human melanocytes stimulates proliferation and melanogenesis. Endocrinology 1996, 137, 1627-1633. [CrossRef] [PubMed]

35. Dong, D.; Jiang, M.; Xu, X.; Guan, M.; Wu, J.; Chen, Q.; Xiang, L. The effects of NB-UVB on the hair follicle-derived neural crest stem cells differentiating into melanocyte lineage in vitro. J. Dermatol. Sci. 2012, 66, 20-28. [CrossRef] [PubMed]

36. Wan, P.; Hu, Y.; He, L. Regulation of melanocyte pivotal transcription factor MITF by some other transcription factors. Mol. Cell Biochem. 2011, 354, 241-246. [CrossRef] [PubMed]

37. Park, S.Y.; Jin, M.L.; Kim, Y.H.; Kim, Y.; Lee, S.J. Aromatic-turmerone inhibits $\alpha$-MSH and IBMX-induced melanogenesis by inactivating CREB and MITF signaling pathways. Arch. Dermatol. Res. 2011, 303, 737-744. [CrossRef] [PubMed] 
38. Lin, M.; Zhang, B.X.; Zhang, C.; Shen, N.; Zhang, Y.Y.; Wang, A.X.; Tu, C.X. Ginsenosides Rb1 and Rg1 Stimulate Melanogenesis in Human Epidermal Melanocytes via PKA/CREB/MITF Signaling. Evid. Based Complement. Altern. Med. 2014, 2014, 892073. [CrossRef] [PubMed]

39. Song, Y.S.; Balcos, M.C.; Yun, H.Y.; Baek, K.J.; Kwon, N.S.; Kim, M.K.; Kim, D.S. ERK Activation by Fucoidan Leads to Inhibition of Melanogenesis in Mel-Ab Cells. Korean J. Physiol. Pharmacol. 2015, 19, 29-34. [CrossRef] [PubMed]

40. Kim, E.S.; Jeon, H.B.; Lim, H.; Shin, J.H.; Park, S.J.; Jo, Y.K.; Oh, W.; Yang, Y.S.; Cho, D.H.; Kim, J.Y. Conditioned Media from Human Umbilical Cord Blood-Derived Mesenchymal Stem Cells Inhibits Melanogenesis by Promoting Proteasomal Degradation of MITF. PLoS ONE 2015, 10, e0128078. [CrossRef] [PubMed]

41. Lee, S.A.; Son, Y.O.; Kook, S.H.; Choi, K.C.; Lee, J.C. Ascorbic acid increases the activity and synthesis of tyrosinase in B16F10 cells through activation of p38 mitogen-activated protein kinase. Arch. Dermatol. Res. 2011, 303, 669-678. [CrossRef] [PubMed]

42. Mizutani, Y.; Hayashi, N.; Kawashima, M.; Imokawa, G. A single UVB exposure increases the expression of functional KIT in human melanocytes by up-regulating MITF expression through the phosphorylation of p38/CREB. Arch. Dermatol. Res. 2010, 302, 283-294. [CrossRef] [PubMed]

43. Ye, Y.; Chu, J.H.; Wang, H.; Xu, H.; Chou, G.X.; Leung, A.K.; Fong, W.F.; Yu, Z.L. Involvement of p38 MAPK signaling pathway in the anti-melanogenic effect of San-bai-tang, a Chinese herbal formula, in B16 cells. J. Ethnopharmacol. 2010, 132, 533-535. [CrossRef] [PubMed]

44. Huang, H.C.; Chang, S.J.; Wu, C.Y.; Ke, H.J.; Chang, T.M. [6]-Shogaol inhibits $\alpha$-MSH-induced melanogenesis through the acceleration of ERK and PI3K/Akt-mediated MITF degradation. BioMed Res. Int. 2014, 2014, 842569. [CrossRef] [PubMed]

45. Smoller, B.R.; McNutt, N.S.; Hsu, A. HMB-45 recognizes stimulated melanocytes. J. Cutan. Pathol. 1989, 16, 49-53. [CrossRef] [PubMed]

46. Busam, K.J.; Jungbluth, A.A. Melan-A, a new melanocytic differentiation marker. Adv. Anat. Pathol. 1999, 6, 12-18. [CrossRef] [PubMed]

47. Hamid, M.A.; Sarmidi, M.R.; Park, C.S. Mangosteen leaf extract increases melanogenesis in B16F1 melanoma cells by stimulating tyrosinase activity in vitro and by up-regulating tyrosinase gene expression. Int. J. Mol. Med. 2012, 29, 209-217. [PubMed]

(C) 2017 by the authors. Licensee MDPI, Basel, Switzerland. This article is an open access article distributed under the terms and conditions of the Creative Commons Attribution (CC BY) license (http:/ / creativecommons.org/licenses/by/4.0/). 